\title{
ASPectos da CUltura italiana nas AULAS DE LÍNGUA PORTUGUESA: REFLEXÕES SOBRE O LIVRO DIDÁTICO
}

\author{
Igor Porsette \& Grace Alves da Paixão*
}

RESUMO: O uso do livro didático (LD) nas aulas de língua portuguesa é uma realidade da maioria das escolas regulares brasileiras. Em muitos casos, trata-se da única ferramenta do(a) professor(a) para subsidiar suas aulas. Este artigo tem como objetivo fazer um levantamento de dados acerca da presença da cultura italiana na coleção de livros didáticos de português para o Ensino Médio: Esferas das linguagens. Para tanto, utilizamos uma abordagem qualitativa, de natureza básica e com objetivos exploratórios e descritivos, já que se trata de um aspecto ainda muito pouco pesquisado nos livros didáticos. A partir disso, a ideia do estudo é refletir sobre como uma formação em Letras, que não se limite ao estudo do Português, mas inclua uma língua e uma literatura estrangeira, pode oferecer ao professor ferramentas capazes de auxiliar também nas aulas de Português. Nosso foco aqui será a cultura italiana pelo papel fundamental que possui na formação da identidade brasileira e pela frequência com a qual referências a essa cultura são utilizadas nos livros didáticos, fato que o manual escolhido para a nossa análise evidencia.

PALAVRAS-CHAVE: Livro didático; Cultura italiana; Ensino Médio; Formação de professores.

ABSTRACT: L'uso dei libri di testo (LD) nelle lezioni di lingua portoghese è una realtà nella maggior parte delle scuole regolari brasiliane. In molti casi, è l'unico strumento a disposizione dell'insegnante come supporto per le sue lezioni. Questo articolo si propone di analizzare dati sulla presenza della cultura italiana in libri di testo di portoghese per la scuola secondaria brasiliana intitolati Esferas das linguagens. A tale scopo, abbiamo utilizzato un approccio qualitativo, di base e con obiettivi esplorativi e descrittivi, dal momento che si tratta di un aspetto ancora poco studiato nei libri di testo. A partire da questa analisi, l'obiettivo dello studio è di riflettere su come una formazio-

* Universidade Federal do Espírito Santo (UFES)

porsette@gmail.com / paixao.grace@gmail.com

DOI: http://dx.doi.org/10.11606/issn.2238-8281.v0i38p39-60 
ne in letteratura, che non si limiti allo studio del portoghese, ma includa una lingua e una letteratura straniera, possa offrire agli insegnanti strumenti in grado di contribuire anche a migliorare le lezioni di portoghese. Il nostro focus qui sarà la cultura italiana a causa del ruolo fondamentale che svolge nella costruzione dell'identità brasiliana e della frequenza con cui i riferimenti a questa cultura vengono utilizzati nei libri di testo, fatto evidenziato dal manuale scelto per la nostra analisi.

PAROLE CHIAVE: Libri di testo; Cultura italiana; Scuola secondaria; Formazione docente.

ABSTRACT: The use of textbooks (LD) in Portuguese language classes is a reality in most Brazilian regular schools. In many cases, it is the teacher's only tool to subsidize their classes. This article aims to survey data about the presence of Italian culture in the collection of textbooks of Portuguese for brazilian high school: Esferas das linguagens. For this purpose, we use a qualitative approach, of a basic nature and with exploratory and descriptive objectives, since it is an aspect that is still understudied in textbooks. From this, the idea of the study is to reflect on how a training in Literature, which is not limited to the study of Portuguese, but includes a foreign language and literature, can offer the teacher tools that can also help in Portuguese classes. Our focus here will be Italian culture due to the fundamental role it plays in the construction of Brazilian identity and the frequency with which references to this culture are used in textbooks, a fact that the manual chosen for our analysis shows.

KEYWORDS: Italian culture; Textbook; High School; Teacher education. 


\section{Introdução}

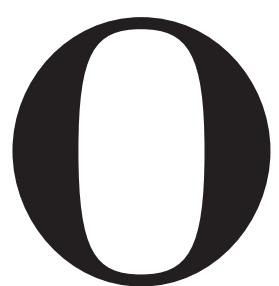

uso do livro didático (LD) nas aulas de língua portuguesa e literatura é uma realidade na maioria das escolas regulares brasileiras. Em muitos casos, trata-se da única ferramenta do(a) professor(a) para subsidiar suas aulas. Como se trata de um elemento muito importante no processo de escolarização, o livro didático vem ganhando cada vez mais a atenção dos pesquisadores, como salientam Freitas e Rodrigues (2008, n.p.):

Algumas pesquisas vêm sendo realizadas ao longo dos anos sobre o livro didático, sobre os seus mais variados aspectos tais como o pedagógico, o político, o econômico e o cultural. A preocupação em pesquisá-lo leva em conta o fato de que o material didático tem uma importância grande na formação do aluno [...]. das 9 seções pesquisadas, em 3 delas

Nesses materiais, os conteúdos propostos apresentam várias referências brasileiras e estrangeiras, no âmbito linguístico-cultural, histórico, social, artístico e literário com as quais o(a) professor(a) deve lidar ao preparar e conduzir suas aulas, no intuito de promover o desenvolvimento de competências gerais previstas na Base Nacional Comum Curricular (BNCC), tais como:

Valorizar e fruir as diversas manifestações artísticas e culturais, das locais às mundiais, e também participar de práticas diversificadas da produção artístico-cultural. (BRASIL, 2018, p. 9)

Utilizar diferentes linguagens - verbal (oral ou visual-motora, como Libras, e escrita), corporal, visual, sonora e digital -, bem como conhecimentos das linguagens artística, matemática e científica, para se expressar e partilhar informações, experiências, ideias e sentimentos em diferentes contextos e produzir sentidos que levem ao entendimento mútuo. (BRASIL, 2018, p. 9) 
O fato de os livros didáticos trazerem diversos elementos de culturas estrangeiras em contato com a brasileira tem também a ver com o Plano Nacional do Livro Didático - alinhado com os objetivos da BNCC - que prevê que os manuais tragam: "contribuições substanciais para a formação cidadã dos estudantes, pautando temas contemporâneos com reconhecimento da diversidade e respeito às diferenças" (PNLD, 2018). Com isso, espera-se que o conteúdo seja plural para que o(a) estudante seja capaz de se reconhecer na diferença, quando do confronto com outras realidades, outros modos de pensar e pontos de vista sobre um mesmo tema. Nesse sentido, a presença da cultura estrangeira nos manuais didáticos de língua portuguesa parece-nos um assunto que requer maior atenção, visto que a nossa cultura é formada por meio da interação com outras e, portanto, reconhecer o estrangeiro é ao mesmo tempo respeitar as diferenças e tomar consciência de que carregamos partes de outros povos.

No Brasil, os cursos voltados à formação de professores de português acabam priorizando a realidade brasileira em diálogo mais estreito com Portugal. Desse modo, tais cursos não procuram prepará-los para lidar com os conteúdos de culturas e literaturas estrangeiras presentes nos livros didáticos, sejam eles relativos aos povos nativos, aos africanos, aos orientais ou aos europeus.

Dentre o leque de referências estrangeiras, a Itália costuma receber a atenção dos autores dos livros didáticos, dada a sua importância para o desenvolvimento do cenário artístico, cultural e literário mundial e também sua relevância no que tange à questão da formação identitária do povo brasileiro, especialmente nas regiões onde houve maior fixação de comunidades oriundas da Itália, a partir dos fluxos migratórios marcantes entre o final do século XIX e até meados do século XX, sobretudo nas regiões Sul e Sudeste do nosso país. ${ }^{1}$ Aspectos culturais ligados ao bel paese surgem nos livros didáticos, sobretudo, nas sessões dedicadas ao ensino da literatura. Mais uma vez, ao evidenciar aspectos relativos à cultura italiana, as autoras parecem querer atender a um dos objetivos da BNCC para o Ensino Médio, isto é, contemplar os estudos e práticas de:

VI - história do Brasil e do mundo, levando em conta as contribuições das diferentes culturas e etnias para a formação do povo brasileiro, especialmente das matrizes indígena, africana e europeia; (BRASIL, 2018, p. 479)

Dentre os povos europeus que mais migraram para nosso país, causando um impacto enorme na constituição cultural do povo brasileiro, os italianos possuem o maior peso. (BRASIL, 2007)

Nesse sentido, este artigo quer apontar as marcas italianas presentes nas sessões Leitura e Literatura da coleção Esferas das linguagens, com vistas a analisar em que medida as referências à Itália podem contribuir para a construção de uma educação intercultural, conforme reflete Vera Candau:

1 Entre 1870 e 1920, ápice do longo período conhecido como "grande imigração", os italianos representam $42 \%$ do número total de imigrantes que entraram no Brasil, ou seja, 1,4 milhão de italianos em 3,3 milhões de imigrantes (ITENETs, 2003, p. 3, tradução nossa). 
A perspectiva intercultural rompe com uma visão essencialista das culturas e das identidades culturais. Concebe as culturas em contínuo processo de elaboração, de construção e reconstrução. Certamente cada cultura tem suas raízes, mas estas raízes são históricas e dinâmicas. Não fixam as pessoas em determinado padrão cultural. (2014, p. 38)

Pretende-se igualmente refletir sobre a importância de o professor de português ter também conhecimentos relativos a aspectos culturais de outros países, sendo que neste artigo o foco das reflexões será a Itália, de modo que enriqueça suas aulas a partir das menções que aparecem ao longo das unidades do manual didático.

Desta feita, acreditamos poder contribuir - a partir de um exemplo específico - para os estudos relativos aos conteúdos presentes nos manuais didáticos, bem como para a necessidade de uma formação mais ampla do professor de língua portuguesa. Pensamos aqui em um percurso que englobe muitos outros saberes, dentre eles o conhecimento dos aspectos culturais da Itália, país de onde saíram inúmeros imigrantes que muito contribuíram para a sociedade brasileira, majoritariamente, no sul e sudeste do Brasil.

Esta pesquisa tem uma abordagem qualitativa, de natureza básica, já que investiga um aspecto ainda não explorado dos livros didáticos, a saber, a presença de aspectos ligados à cultura italiana, com objetivos exploratórios e descritivos (GIL, 2002; MARCONI \& LAKATOS, 2003). Para tanto, analisamos a coleção Esferas das linguagens (2016), composta de três volumes, voltados para o Ensino Médio, observando citações, trechos de livros, indicações de leitura, obras cinematográficas e ilustrações de arte.

\section{Apresentação dos manuais}

Para que um manual didático de língua portuguesa seja distribuído para uso nas escolas brasileiras, é necessário que seja aprovado, previamente, pelo Plano Nacional do Livro Didático (PNLD). O PNLD, tem como função avaliar e selecionar por meio de critérios técnicos e científicos os livros que são distribuídos para todas as escolas do Ensino Fundamental e Médio.

Esferas das Linguagens, aprovada em 2018, é uma coleção formada por três volumes destinados ao Ensino Médio.

Cada um deles apresenta três eixos que sustentam os conteúdos a serem trabalhados ao longo dos três anos letivos: literatura, produção de textos e gramática em uso, conforme informação destacada já na capa (Figura 1). 
Figura 1: Capas dos volumes da Coleção Esferas das Linguagens



Os volumes são organizados em nove unidades didáticas, sendo que cada uma delas possui três capítulos: Leitura e literatura; Texto, gênero do discurso e produção; Língua e linguagem. A Figura 2, abaixo, traz um excerto do Sumário do primeiro volume da coleção e pode melhor dar uma ideia ao leitor da divisão do livro em Unidades Didáticas e, dentro das unidades, capítulos organizados por eixos temáticos. 
Figura 2: Excerto do Sumário do Primeiro volume da Coleção Esferas das Linguagens

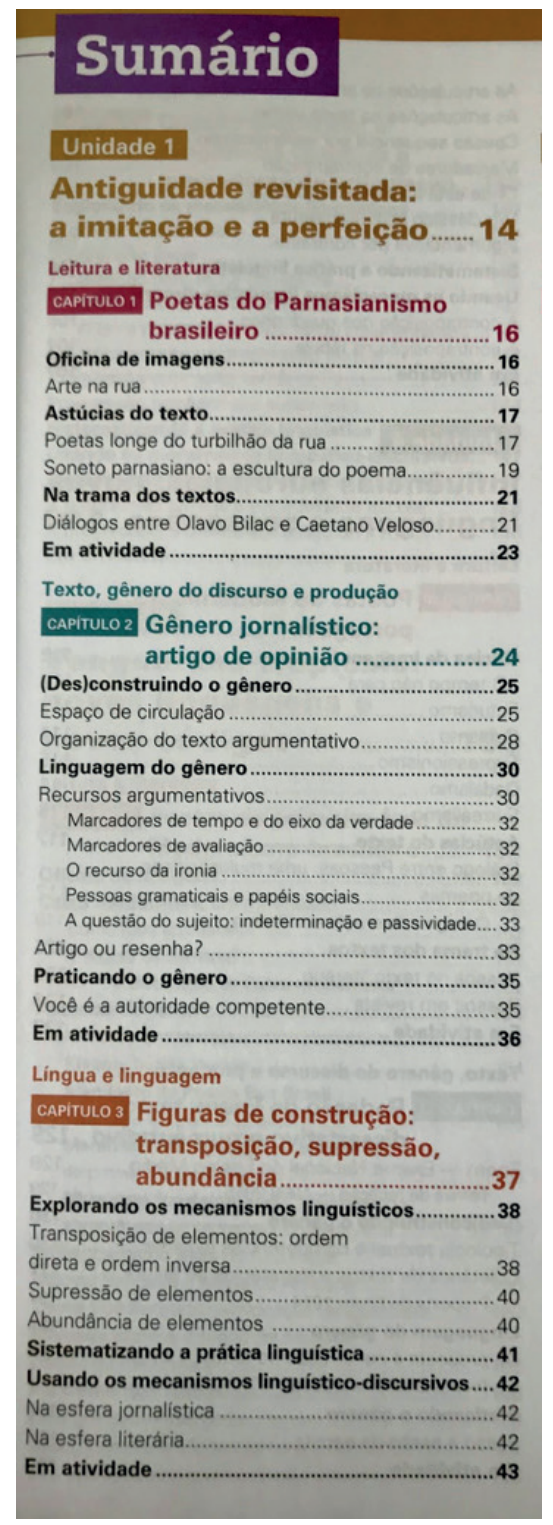


Em cada livro há nove capítulos dedicados, por assim dizer, à literatura: trata-se dos capítulos inseridos na seção Leitura e Literatura, os quais, por sua vez, são subdivididos em três tópicos: Oficinas de imagens; Astúcias do texto e Na trama dos textos; cada um com um propósito específico em consonância ao aprendizado proporcionado pelos conteúdos a serem trabalhados pelos (as) professores (as).

Segundo as autoras, o tópico Oficina de imagens tem a seguinte proposta:

Sensibilizar o aluno para o tema de leitura ou texto literário que será apresentado. Há uma variedade de imagens (pinturas, esculturas, fotografias, iluminuras, desenhos, mapas, grafites, cartazes, capas de livros etc.) para auxiliar na sensibilização em relação ao tema e para o desenvolvimento da leitura do texto visual. [...] (CAMPOS; ASSUNÇÃO, 2016, n.p.)

Já Astúcias do texto "tem como foco a leitura e a compreensão de textos de vários gêneros: histórias em quadrinhos, charges, notícias de jornal, reportagens, resenhas e, principalmente, produções literárias." (CAMPOS; ASSUNÇÃO, 2016, n.p). Por fim, "a finalidade da seção Na trama dos textos é proporcionar um diálogo entre os textos literários e os textos fílmicos, canções, quadrinhos, charges etc.” (CAMPOS; ASSUNÇÃO, 2016, n.p).

Neste artigo, nosso olhar recai especificamente sobre as seções Leitura e Literatura, por considerarmos que nelas há maior possibilidade de haver referências a diferentes artes e culturas. Tais seções configuram-se campos propícios para a inserção de fatos, dados, informações e conteúdos relacionados à cultura estrangeira, proporcionando conhecimentos de literatura em relação com esferas maiores do campo cultural. Por um lado, é relevante que os jovens compreendam a formação da literatura brasileira (e da cultura brasileira, de um modo geral) a partir de sua interação com outras literaturas e culturas. Por outro lado, os(as) estudantes do Ensino Médio estão cada vez mais em contato com literaturas de fora, seja por meio de livros físicos ou digitais, seja por meio de aplicativos de leitura, plataformas de compartilhamento de vídeos, ou ainda obras literárias adaptadas de filmes ou séries televisivas.

Apesar de o livro ser voltado para o ensino de língua portuguesa, as propostas das autoras não se restringem apenas ao contexto brasileiro, mas procuram trazer reflexões acerca dos aspectos socioculturais de outros povos, tanto para o enriquecimento da cultura geral, quanto para o estabelecimento de relações entre a cultura do Brasil e as demais. Isso permite que a escola possa organizar a progressão curricular de modo a atender a alguns dos parâmetros previstos na BNCC:

Diversificar, ao longo do Ensino Médio, produções das culturas juvenis contemporâneas (slams, vídeos de diferentes tipos, playlists comentadas, raps e outros gêneros musicais etc.), minicontos, nanocontos, best-sellers, literaturas juvenis brasileira e estrangeira, incluindo entre elas a literatura africana de língua portuguesa, a afro-brasileira, a latino-americana etc., obras 
da tradição popular (versos, cordéis, cirandas, canções em geral, contos folclóricos de matrizes europeias, africanas, indígenas etc.) que possam aproximar os estudantes de culturas que subjazem na formação identitária de grupos de diferentes regiões do Brasil. (BRASIL, 2018, p. 526).

\section{Podemos comprovar essa preocupação na apresentação do livro:}

[...] você vai experimentar como um texto literário pode ser lido de várias maneiras e como ele dialoga também com textos de outras épocas. Seu mundo ficará muito mais rico e divertido e você conhecerá autores, personagens e lugares fascinantes. (CAMPOS; ASSUNÇÃO, 2016, n.p., v. 1)

É nessa perspectiva que pretendemos observar a presença de conteúdos ligados à Itália ao longo das unidades didáticas, no intuito de responder questões como: quais aspectos da cultura italiana são destacados? Onde e como estão inseridos nas unidades? De que maneira a formação do professor de português pode influir na abordagem de tais elementos?

Antes de apresentarmos os dados, é importante salientar o modo como a literatura é trabalhada na seção Leitura e literatura: no volume 1, claramente não se obedece a um formato tradicional de ensino baseado em periodização literária. Os conteúdos são abordados transversalmente, de modo a atender às competências previstas no documento do MEC Matriz de Referência para o Enem, conforme consta na seção Orientações para o professor ao final do livro. Nos volumes 2 e 3 , por sua vez, as autoras mantêm uma perspectiva tradicional dos períodos literários, no que tange ao ensino da literatura sem, no entanto, perderem de vista as competências a serem desenvolvidas ao longo do percurso formativo. ${ }^{2}$

Ao que tudo indica, a ideia é sensibilizar os(as) estudantes para lidar com textos literários no primeiro ano do Ensino Médio e, posteriormente, nos segundo e terceiro anos, inseri-los nos estudos mais específicos sobre autores(as) e correntes literárias em relação a períodos canonicamente consagrados do Trovadorismo ao Modernismo. Por isso, a presença da cultura italiana está disseminada entre os vários conteúdos dispostos no livro, sem a pretensão clara de ser “ensinada", posto que se trata de um livro preparado para as aulas de Língua Portuguesa.

\section{Levantamento dos dados}

Tendo realizado o levantamento dos dados na coleção em foco, organizamos as menções à Itália nos seguintes temas: língua, literatura, artes plásticas, história e música, conforme a tabela abaixo:

2 As autoras afirmam nas Orientações ao professor que os conteúdos da seção Leitura e Literatura foram pensados para atender à Matriz de Referência para o Enem. No volume 1, o foco está nas competências 4, 5 e 6; no volume 2, está nas competências 5, 6 e 8. E, com relação ao Volume 3, as competências visadas são 4, 5, 6. (BRASIL, 2015) 
Tabela 1: Disposição geral das referências italianas nos três volumes.

\begin{tabular}{|c|c|c|c|c|c|c|}
\hline & Volume & Língua & Literatura & Artes plásticas & História & Música \\
\hline \multirow{3}{*}{$\begin{array}{l}\text { Un. } 1 \text { - } \\
\text { cap. } 01\end{array}$} & 1 & - & - & - & - & - \\
\hline & 2 & - & 2 & - & - & - \\
\hline & 3 & - & 1 & - & - & - \\
\hline \multirow{3}{*}{$\begin{array}{l}\text { Un. } 2 \text { - } \\
\text { cap. } 04\end{array}$} & 1 & 1 & - & - & - & - \\
\hline & 2 & - & - & - & - & 1 \\
\hline & 3 & - & - & - & - & - \\
\hline \multirow{3}{*}{$\begin{array}{l}\text { Un. } 3 \text { - } \\
\text { cap. } 07\end{array}$} & 1 & - & - & 2 & - & - \\
\hline & 2 & - & - & - & - & - \\
\hline & 3 & - & - & - & - & - \\
\hline \multirow{3}{*}{$\begin{array}{l}\text { Un. } 4 \text { - } \\
\text { cap. } 10\end{array}$} & 1 & - & 2 & - & - & - \\
\hline & 2 & - & & 1 & - & - \\
\hline & 3 & - & 2 & 5 & - & - \\
\hline \multirow{3}{*}{$\begin{array}{l}\text { Un. } 5 \text { - } \\
\text { cap. } 13\end{array}$} & 1 & - & - & - & & - \\
\hline & 2 & - & - & - & 1 & - \\
\hline & 3 & - & - & - & & - \\
\hline \multirow{3}{*}{$\begin{array}{l}\text { Un. } 6 \text { - } \\
\text { cap. } 16\end{array}$} & 1 & - & - & - & - & - \\
\hline & 2 & - & 1 & 2 & - & - \\
\hline & 3 & - & 1 & - & - & - \\
\hline \multirow{3}{*}{$\begin{array}{l}\text { Un. } 7 \text { - } \\
\text { cap. } 19\end{array}$} & 1 & - & - & - & - & - \\
\hline & 2 & - & - & 1 & - & - \\
\hline & 3 & - & - & - & - & - \\
\hline \multirow{3}{*}{$\begin{array}{l}\text { Un. } 8 \text { - } \\
\text { cap. } 22\end{array}$} & 1 & - & - & - & - & - \\
\hline & 2 & - & - & - & - & - \\
\hline & 3 & - & - & - & - & - \\
\hline \multirow{3}{*}{$\begin{array}{l}\text { Un. } 9 \text { - } \\
\text { cap. } 25\end{array}$} & 1 & - & - & - & - & - \\
\hline & 2 & - & 1 & - & - & - \\
\hline & 3 & - & - & - & - & - \\
\hline
\end{tabular}


Considerando os três volumes, encontramos 27 seções Leitura e literatura. Em 14 delas, há menções à Itália no tocante aos seguintes âmbitos: língua, literatura, artes plásticas, história e música. Isso significa que em $51,85 \%$ das seções Leitura e literatura o professor se depara com conteúdos do campo da italianística.

Se analisarmos os volumes separadamente, temos a seguinte configuração:

Tabela 2: Percentual de referências à Itália, por seção.

\begin{tabular}{|c|c|c|c|}
\hline Volume & $\begin{array}{c}\text { Seção Leitura e } \\
\text { literatura (total) }\end{array}$ & $\begin{array}{c}\text { Seção Leitura e literatura } \\
\text { (conteúdo Itália) }\end{array}$ & $\begin{array}{c}\text { Percentual (conteúdo } \\
\text { Itália) }\end{array}$ \\
\hline 1 & 9 & 4 & $44,44 \%$ \\
\hline 2 & 9 & 7 & $77,77 \%$ \\
\hline 3 & 9 & 3 & $33,33 \%$ \\
\hline
\end{tabular}

Analisando as 9 seções Leitura e literatura que compõem o volume 1, vemos que em 4 delas aparecem menções com conteúdos relativos à Itália, o que equivale a 44,44\% de seções que abordam aspectos da cultura italiana. Já no volume 2, em 7 das 9 seções em estudo, há referências ao universo dos estudos italianos, o que quantitativamente significa que $77,77 \%$ das seções trazem algo dessa temática. Por fim, no volume 3 , observamos marcas da italianidade em 3 das 9 seções pesquisadas, ou seja, 33,33\% das seções contêm elementos que remetem àquele país.

No que diz respeito aos elementos temáticos abordados e considerando os três volumes que compõem a coleção estudada, temos a seguinte amostra:

Tabela 3: Percentual de menções à área da Italianística dividido por temas.

\begin{tabular}{|c|c|c|c|c|c|}
\hline & Língua & Literatura & Artes plásticas & História & Música \\
\hline $\begin{array}{c}\text { Menções conteúdos } \\
\text { da Italianística } \\
\text { (Total: 24) }\end{array}$ & $01(4,16 \%)$ & $10(41,66 \%)$ & $11(45,83 \%)$ & $01(4,16 \%)$ & $\begin{array}{c}01 \\
(4,16 \%)\end{array}$ \\
\hline
\end{tabular}

Ao todo, encontramos, portanto, 24 menções que dizem respeito à língua, à literatura, às artes plásticas, à história e à música italianas. A partir da tabela, podemos perceber que os eixos 
"literatura" e "artes plásticas" são mais utilizados para abordar aspectos literários e/ou culturais do Brasil em confronto com aqueles italianos. Por outro lado, os eixos "língua", "história" e "música" são numericamente menos expressivos, ainda que o espaço de discussão para esses elementos seja mais significativo como iremos abordar mais adiante.

Gráfico 1: Proporção de referências à Itália dividida por temas (valores arredondados)

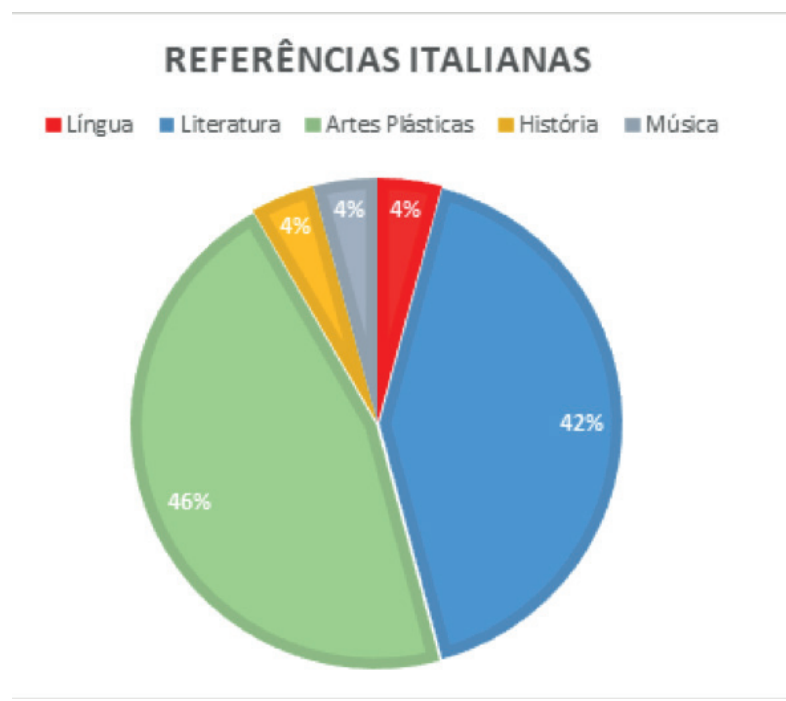

Com o objetivo de refletir de que modo esses elementos são abordados, iremos nos deter em cada um deles separadamente, levando em consideração os três volumes.

\subsection{Menções à língua italiana}

A primeira referência voltada para a Itália, aparece na unidade 2, capítulo 4, do volume 1, trabalhado no primeiro ano do Ensino Médio. Essa unidade, cujo título é Construção da brasilidade: as raízes e o cidadão, é perpassada pela ideia de trabalhar as "[...] raízes culturais daqueles que chegaram ao Brasil e encontraram um povo com língua e costumes diferentes" (CAMPOS \& ASSUNÇÃO, 2016, p.41). Observamos na apresentação da unidade um viés dedicado à língua, sobretudo à construção da língua brasileira. Nesse sentido, as autoras propõem, com um trecho de Brás, Bexiga e Barra Funda (de Antônio de Alcântara Machado), uma aproximação entre a variante brasileira coloquial e a variante ítalo-paulistana, a fim de exemplificar uma realidade linguística da cidade de São Paulo dos anos 1920. Com isso, a 
Italianidade aparece como pano de fundo no aspecto linguístico, ao serem evidenciadas as contribuições do italiano para a formação do português brasileiro - de modo especial em São Paulo - com o processo de imigração.

Com isso, as autoras chamam à reflexão sobre o contato linguístico com a língua italiana, tanto em relação às palavras que foram incorporadas à variante brasileira do português, quanto àquelas que se tornaram "transparentes" devido ao uso, relativamente, rotineiro na língua portuguesa como: bambino, al dente.

No volume 3, destinado ao terceiro ano do Ensino Médio, a narrativa de Alcântara Machado é novamente citada, porém com o viés prioritariamente literário, uma vez que a unidade 6 trata da cultura artística da Belle époque. Brás, Bexiga e Barra Funda mostra o que as autoras chamam de "pequenos quadros urbanos" e apresenta ao público um novo tipo na literatura brasileira: o ítalo-brasileiro. Mais uma vez, somos convidados a considerar a cultura italiana como um elemento formador e, portanto, marcante, da cultura brasileira em sua vertente paulista.

Desse modo, é importante salientar que um professor graduado também em italiano poderia estabelecer, de maneira mais natural, relações entre a formação do português do Brasil a partir da aproximação com a língua italiana. Obviamente, seja qual for a formação do professor de português, é preciso que este faça pesquisas no intuito de preparar suas aulas de acordo com os temas trazidos pelo manual didático. Em outras palavras: faz parte do trabalho do professor, ao ter em mãos o livro didático a ser trabalhado em sala de aula, analisá-lo e estudá-lo de maneira a enriquecê-lo e torná-lo palpável e interessante para os estudantes, considerando vários elementos que têm a ver com o contexto em que a escola (e todos os atores sociais que nela atuam) está inserida.

Logo, ter a formação em Letras Italiano não é condição sine qua non para que tais informações acerca dos contatos linguísticos Brasil-Itália sejam levados à sala de aula, mas seria desejável que mesmo os professores sem uma formação em italiano busquem referências de maneira independente para aulas desse tipo.

No caso de um docente que possui tal formação, podemos prever que, ao se deparar com elementos linguísticos italianos presentes no português brasileiro, ele conseguirá tanto se apropriar desses elementos, quanto enriquecer as aulas trazendo outros conteúdos que permitam refletir sobre a importante contribuição do povo italiano para a criação de uma identidade brasileira, no que tange ao aspecto linguístico, entre outros.

\subsection{Menções à literatura}

As referências à literatura italiana aparecem, primeiramente, na unidade 4 do volume 1 cujo título é: Eu e o outro: subjetividade e ação, capítulo 10. A proposta desta unidade é apresentar para o primeiro ano do Ensino Médio estruturas das novelas de cavalaria e elementos da cultura medieval. As autoras partem dos espanhóis Picasso e Cervantes, abrindo a unidade com a ilus- 
tração Dom Quixote de La Mancha (1955), de Picasso, e um texto que relaciona a imagem à obra de Cervantes.

Nesse contexto, as autoras inserem uma discussão sobre as relações entre o real e o fantástico nos textos literários e, para tanto, o conto O Cavaleiro Inexistente (1959), do italiano Italo Calvino, recebe destaque especial. O conto é apresentado pelas autoras como uma novela de cavalaria que não segue os moldes tradicionais do período medieval, mas é subvertida pelo olhar moderno do autor. Aparece, novamente, uma menção a Calvino no volume 2, unidade 9 (Olhares sobre a cidade: habitações coletivas), capítulo 25. Já se havia discutido Calvino no primeiro ano do Ensino Médio e volta-se a estudá-lo no segundo ano. A proposta da seção é trabalhar a prosa naturalista brasileira especialmente as características da obra de Aluísio de Azevedo: $O$ cortiço. Para tanto, inicia-se uma reflexão sobre as diferentes configurações das cidades e é nesse momento que a obra de Calvino ganha relevância.

É em tal contexto que trazem à tona um excerto da obra calviniana, As cidades invisíveis. Trata-se de um segundo momento em que as autoras recorrem à literatura desse autor fazendo com que sejam apresentados trechos de suas obras, desta vez, com vistas a utilizá-lo como ponto de partida para uma discussão mais aprofundada acerca de um aspecto marcante da obra naturalista: a questão do meio em que se vive nas cidades.

Ainda no volume 2, a Itália surge na unidade 1: Galáxias do livro: do manuscrito à impressão, capítulo 1. A proposta da seção Leitura e literatura é "estudar a poesia galego-portuguesa e o teatro popular de Gil Vicente [...] [e também] a poesia lírica de Luís Vaz de Camões" (CAMPOS; ASSUNÇÃO, 2016, p.15,v.2). Por isso, as autoras apresentam diferentes coletâneas e manuscritos medievais em que tais textos podem ser encontrados: um deles é o Cancioneiro da Vaticana. Desse modo, os(as) estudantes podem ser convidados a refletirem sobre as primeiras instituições de preservação de manuscritos do mundo, situada no atual Vaticano (território que pertenceu a Roma até 1929).

No volume 3, destinado ao terceiro ano do Ensino Médio, encontramos algumas outras menções à literatura italiana. A primeira delas se refere a Dante Alighieri, na unidade 1 (Antiguidade revisitada: a imitação e a perfeição), capítulo 1, que pretende trabalhar o parnasianismo brasileiro. As autoras trazem uma imagem d' $O$ pensador, de Rodin, esculpida em homenagem ao poeta italiano, explicando no texto de apresentação, a relação entre aquela escultura e a Divina Comédia, uma vez que a personagem principal (Dante) se encontra em atitude reflexiva diante do portal do inferno. Essa narrativa de Dante tem uma grande representatividade para os italianos, já que é considerada a primeira obra escrita no que viria a ser a língua italiana. Além disso, é considerada um texto importante para a cultura cristã por conta das suas imagens sobre o inferno, o purgatório e o paraíso. Trata-se, portanto, de uma oportunidade se apresentar a obra Divina Comédia que muito contribuiu para a literatura ocidental.

Posteriormente, na unidade 4 do mesmo volume (Influências Europeias: novas linguagens e sensações), no capítulo 10, as autoras trazem a presença de Marinetti. O intuito da seção em foco é o estudo de tendências artísticas europeias do início do século XX. Nesse sentido, o 
manifesto futurista, escrito pelo italiano em 1909, é um dos elementos trazidos como ponto de partida para se pensar o futurismo considerado um dos primeiros movimentos da arte moderna.

Para tanto, convida-se à leitura de um excerto do Manifesto futurista, a fim de que se possa entender o espírito dessa corrente de época tão expressiva para as artes brasileiras. Com isso, os(as) estudantes são levados a refletir sobre os traços dessa vanguarda nas várias manifestações artísticas apresentadas ao longo da seção e, portanto, o diálogo frequente da cultura italiana com a cultura brasileira.

A partir das menções elencadas, fica evidente que o professor com formação em italiano teria mais familiaridade com os autores e temas propostos pelo manual, sendo, portanto, mais apto a lidar com conteúdos de literatura italiana e seus diálogos com a literatura brasileira. Obviamente, essa possibilidade de aproximação entre aspectos culturais italianos e brasileiros não fica restrita ao professor com formação em italiano: qualquer professor com uma boa formação crítica estará habilitado a lidar com diversos textos e a apresentá-los aos seus alunos de maneira a diversificar os conhecimentos literários.

O que afirmamos em nossa reflexão é que o docente com formação em italiano, tendo estudado mais detidamente Dante, Marinetti e Calvino em nível de graduação, poderia enriquecer as aulas com temas abordados nas obras estrangeiras e que reverberam na literatura brasileira, mostrando as intertextualidades entre as literaturas e proporcionando, já no Ensino Médio, uma formação mais ampla e fora do eixo português.

\subsection{Menções às artes plásticas italianas}

As primeiras referências ligadas às artes plásticas produzidas na Itália aparecem na unidade 3, capítulo 7 do volume 1. Na apresentação desta unidade, cujo título é Asas da imaginação: indivíduo e consumo, as autoras anunciam uma reflexão sobre o valor da obra de arte que "[...] abrange todas as atividades de uma cultura em que se trabalham o sensível e o imaginário, com o objetivo de recuperar a dimensão simbólica de um povo ou de uma classe social [...]." (CAMPOS; ASSUNÇÃO, 2016, p.67, v.1)

A presença italiana se mostra em dois momentos: o primeiro, quando as autoras recorrem aos conceitos de litografia do estudioso da arte Giulio Carlo Argan, referência, principalmente, sobre arte medieval e renascentista; o segundo, quando utilizam uma pintura renascentista do monge florentino Fra Filippo, Retrato de um homem e de uma mulher na janela, de 1440 como ponto de partida para evidenciar a apropriação de uma imagem artística para a confecção da capa de um livro. Assim, as autoras propiciam a possibilidade de se entrar em contato com o Renascimento italiano, uma vez que esse período consagra a Itália como uma referência nas artes plásticas. Partindo da obra de Fra Filippo, busca-se salientar a problematização da arte e seu consumo, ou seja, evidencia o fato de que esta pode ser encontrada não somente em espaços destinados, tradicionalmente, à exposição de objetos artísticos, como museus, mas também em diversos contextos, como propagandas publicitárias, capas de livro e demais formas de 
consumo.

Além de trazer à baila o Renascimento italiano, quer-se discutir as apropriações que a indústria da propaganda e da publicidade, na atualidade, faz da arte no intuito de promover o consumo, criando dessa maneira novos sentidos para a produção artística, num contexto diverso de sua criação original. O professor, a partir do material didático, é levado a refletir, junto com os(as) estudantes, sobre as obras de arte fora de seu contexto e empregadas como pretexto para um outro fim, não previsto pelo seu criador.

Ainda no volume 1, as alusões à Itália aparecem na unidade 6, intitulada Mundo das linguagens: os textos e os contextos, capítulo 16. O objetivo da seção de Leitura e literatura é o estudo das epopeias, com vistas a destacar as características desse gênero literário. Para tanto, as autoras partem da obra de uma artista ítalo-brasileira, Maria Bonomi, intitulada Epopeia Paulista. Esse painel de 73 metros "expressa o desejo de narrar a memória da cidade de São Paulo por intermédio de reminiscências individuais de pessoas anônimas que já chegaram ou continuam chegando à Estação da Luz" (CAMPOS; ASSUNÇÃO, 2016, p.160, v.1), conforme explicação das próprias autoras.

Fica bastante evidente, até aqui, que, por meio das marcas da língua (a variante ítalo-brasileira), da literatura (Brás, Bexiga e Barra Funda) e das artes plásticas (Epopeia Paulista), encontram-se no primeiro ano do Ensino Médio possibilidades de conhecer e discutir a importância do contato com a Itália para a formação da identidade brasileira, em particular, do povo paulista.

Em geral, o professor de português chega à sala de aula sem ter tido uma formação específica para lidar com as artes plásticas ou com o ensino da história da arte, mas a formação em Letras lhe permite abordar transversalmente tais assuntos, seja por meio da semiótica, seja por meio da análise do discurso, seja por meio da história da literatura, sempre em relação às outras produções artísticas. Assim, não costumam faltar aos docentes os conhecimentos necessários para levarem à sala de aula leituras interessantes da produção artística.

Como a Itália é considerada mundialmente um dos países de referência artística, que influenciaram sobremaneira grande parte da arte ocidental, é bastante comum que as obras italianas constem nos livros didáticos como ponto de partida para uma reflexão sócio-histórico-literária. Por isso, o professor com formação em italiano que lida, desde seus primeiros estudos com os elementos artísticos da cultura italiana, poderia ir além dos conteúdos apresentados pelo livro didático.

É sutil o outro exemplo da presença da arte plástica italiana, nesse mesmo primeiro volume da coleção: trata-se de um afresco do pintor neoclássico Luigi Sabatelli, Olimpo (1819-1820), que retrata uma reunião dos deuses no Olimpo no contexto da Guerra de Tróia. Parece-nos que a imagem dessa obra, inserida em um resumo d'Os Lusíadas, de Camões, teve o objetivo de representar a atuação dos deuses nas empreitadas de Vasco da Gama, na narrativa camoniana. Cabe ao professor estreitar as relações intertextuais apresentadas, de modo a aumentar o conhecimento de mundo dos(as) estudantes, isto é, levá-los(as) a apreender um conteúdo pelo qual 
talvez eles não se interessariam fora da sala de aula.

No volume 2, a arte italiana aparece no capítulo 10 da unidade 4 (Espaço social: liberdade e manifestos) com a proposta de estudar o Romantismo de Portugal e do Brasil. Neste momento, as autoras partem de uma reflexão sobre representações, máscaras e identidade, traços importantes das diversas correntes românticas. É nessa perspectiva que são apresentadas várias máscaras de diferentes culturas, entre elas, a máscara veneziana. Este elemento marcante da cultura vêneta, serve de ilustração para exemplificar uma característica do período romântico português e brasileiro que será aprofundado ao longo da seção: a individualidade do ser e seus modos peculiares de expressão.

Ainda no volume 2, podemos encontrar uma outra ocorrência sobre as artes italianas, na unidade 7 (Sonho e realidade: o trabalho e o ócio), capítulo 19, cuja finalidade é o estudo do Realismo. A referência encontra-se ao final da seção, quando as autoras apresentam questões de vestibular. Em uma delas, há um excerto da obra de Giulio Carlo Argan, a fim de refletir sobre as artes no século XIX.

Vale destacar que Argan, teórico e crítico de arte italiano, é referenciado duas vezes: no volume 1, com o livro História da arte italiana (Cosac \& Naify, 2004) e no volume 2, Arte Moderna: do Iluminismo aos movimentos contemporâneos (Cia das Letras, 1992). Isso reforça que, de certo modo, a Itália é considerada referência das artes, uma vez que as autoras recorrem a pinturas, gravuras, imagens e trechos de obras críticas como argumento de autoridade na exposição daquela temática.

Por fim, o volume 3, no capítulo dedicado às vanguardas artísticas europeias do século XX, destaca-se pela riqueza de exemplos ligados à arte italiana. As autoras citam artistas futuristas como: Umberto Boccioni, Carlo Carrà, Luigi Russolo, Giacomo Balla e Gino Severini. Todos eles retrataram em suas artes a questão da velocidade e do anseio pelo futuro a ponto de lançarem um manifesto futurista próprio da pintura, conforme as autoras explicitam ao apresentarem os artistas italianos.

Tudo isso leva a refletir sobre a importância da formação do profissional de Letras. Quanto mais rica e variada, mais terá condições de promover conhecimentos relacionados à língua e à literatura, estabelecendo relações entre diversos campos do saber. Nesse sentido, a formação em Letras Italiano, por exemplo em licenciaturas duplas Português e Italiano, configura-se como um aporte ao docente, que mais naturalmente apreende os elementos da cultura italiana presentes transversalmente no livro didático e, graças à sua bagagem, pode apropriar-se deles para partilhar conhecimentos de maneira didática.

\subsection{Menções à história}

Nos três volumes da coleção Esferas das Linguagens, tendo em perspectiva as seções de Leitura e Literatura, encontramos uma referência a um personagem da história italiana: uma menção a Cristóvão Colombo, que é citado no volume 2, unidade 5 (Imprensa e leitor: constru- 
ção da brasilidade), capítulo 13 cujo objetivo é o estudo do Romantismo brasileiro.

Apesar de Colombo ser associado às navegações ibéricas, o professor tem a oportunidade de destacar a importância histórica desse personagem italiano para o ocidente, em especial, para o Brasil. Importância essa que não se revela apenas na história da nossa formação territorial, mas também na inspiração literária de alguns de nossos poetas românticos. Para tanto, é apresentada a última estrofe do poema de Castro Alves, Navio Negreiro:

Fatalidade atroz que a mente esmaga!

Extingue nesta hora o brigue imundo

O trilho que Colombo abriu nas vagas,

Como um íris no pélago profundo!

Mas é infâmia demais! ... Da etérea plaga

Levantai-vos, heróis do Novo Mundo!

Andrada! arranca esse pendão dos ares!

Colombo! fecha a porta dos teus mares!

A partir do trecho, as autoras elaboram questões de interpretação sobre o poema. Objetivam, assim, levar os estudantes a relacionarem o patriarca da independência brasileira (Andrada: designando José Bonifácio de Andrada Santos) ao navegador italiano (Colombo: designando Cristóvão Colombo), considerados heróis por Castro Alves, no contexto do clamor pelo fim do tráfico negreiro. Ao formularem as questões, as autoras do manual afirmam que Colombo é espanhol:

Na última estrofe, o eu poético invoca dois nomes públicos: Andrada e Colombo. O primeiro é o brasileiro José Bonifácio de Andrada e Silva, que condenou o trabalho escravo e valorizou o trabalho livre, mostrando-se contrário a todas as formas de absolutismo. Foi considerado o "patriarca da independência". O segundo é o espanhol Cristóvão Colombo, que, no século XV, se empenhou em viabilizar a navegação do Atlântico. Como você interpreta essa invocação? (CAMPOS \& ASSUMPÇÃO, 2016, v. 2, p. 161, itálico nosso)

É comum que seja atribuída a Colombo a nacionalidade espanhola, uma vez que o navegador genovês empreendeu suas viagens marítimas sob as ordens de reis espanhóis. Acreditamos que um professor que tenha tido formação em Letras Italiano possa, ao observar tal informação, retificá-la, explicando que o navegador é, na verdade, italiano. 


\subsection{Menções à música italiana}

No que tange à música, as autoras recorrem a Vivaldi na Unidade 2 (Espaço e tensões: $o$ simbólico e a reflexão), capítulo 4, do volume 2, cuja finalidade é tratar do estilo Barroco português e brasileiro. O músico italiano, e sobretudo a obra As Quatro Estações, aparecem como um exemplo de um elemento da música barroca, ao lado dos alemães Bach e Händel. Portanto, os(as) estudantes são convidados a apreciar um dos maiores expoentes da música italiana e, por extensão, mundial. Os aspectos intrínsecos ao Barroco - tais como o rebuscamento, os contrastes, as variações de ritmos e formas - são dessa maneira evidenciados não apenas no universo da literatura, mas também em outras artes: arquitetura, pintura e música.

Desse modo, o professor formado em italiano - talvez mais facilmente - poderia associar características do universo musical, tendo como expoente a figura de Vivaldi, às do universo literário, já que a música tem uma grande representatividade para a cultura italiana, perpassando os âmbitos religioso e teatral/literário. Mais uma vez, é preciso salientar que não se espera - e nem se poderia esperar - do(a) professor(a) uma formação específica em Música para lidar com os conteúdos do livro didático a ela relacionados. O mesmo vale para a História e para as Artes Plásticas. Contudo, a BNCC, ao inserir o componente língua portuguesa na categoria Linguagens, estabelece que as várias linguagens da expressão humana sejam trabalhadas em sala de aula de modo articulado, em interrelação umas com as outras. Música e Literatura fazem parte de um mesmo campo, o artístico:

O campo artístico é o espaço de circulação das manifestações artísticas em geral, contribuindo para a construção da apreciação estética, significativa para a constituição de identidades, a vivência de processos criativos, o reconhecimento da diversidade e da multiculturalidade e a expressão de sentimentos e emoções. Possibilita aos estudantes, portanto, reconhecer, valorizar, fruir e produzir tais manifestações, com base em critérios estéticos e no exercício da sensibilidade. (BRASIL, 2018, p. 491)

Ao entrarem em contato com Vivaldi, sua música e sua personalidade históricas, sua contribuição para o desenvolvimento da música no ocidente, sua presença no Brasil atual, os jovens têm a oportunidade de construir capacidade de apreciação estética e reconhecer a diversidade e a multiculturalidade na expressão de sentimentos e emoções. Para isso, a mediação do(a) professor é fundamental.

\section{Conclusão}

Após a análise da presença de elementos da cultura italiana na coleção Esferas das Linguagens (nas seções de Leitura e Literatura) constatamos que existe, ao longo dos três volumes, uma presença recorrente de aspectos relacionados à língua, à literatura, às artes plás- 
ticas, à história e à música italianas.

A primeira conclusão a que chegamos é a de que tais referências podem propiciar um material que estimule uma educação intercultural, uma vez que as informações sobre a cultura estrangeira - e não apenas a italiana - formam uma espécie de mosaico cultural nos livros, em que estão em consonância diversas artes, culturas e literaturas. Concordamos com Lajolo quando afirma que:

Em sociedades como a brasileira, livros didáticos e não-didáticos são centrais na produção, circulação e apropriação de conhecimentos, sobretudo dos conhecimentos por cuja difusão a escola é responsável. Dentre a variedade de livros existentes, todos podem ter - e efetivamente têm - papel importante na escola. (LAJOLO, 1996, p. 3-4)

A segunda conclusão é a de que, embora haja elementos italianos ao longo do manual, muitos deles aparecem como ilustração ou pretextos para atividades linguístico-literárias. O manual, nem sempre, apresenta de maneira aprofundada a relação entre as menções à Itália e o conteúdo a ser estudado, de modo que cabe ao condutor das aulas preencher essa lacuna e estabelecer as correspondências entre as diferentes culturas e linguagens. Assim, quando olhamos somente para os conteúdos relativos à cultura italiana nos livros didáticos de língua portuguesa, parece-nos certo afirmar que o professor que possui formação também em italiano teria mais condições de enriquecer os conteúdos com informações complementares, de modo a promover uma reflexão e, consequentemente, ir além dos temas apresentados. Nesse sentido, a condução do(a) professor(a) é essencial para que haja um diálogo efetivo entre as várias referências estrangeiras e brasileiras.

Bem articuladas com os conteúdos de língua portuguesa, as referências italianas funcionariam como oportunizadoras "(...) para a criação e o encontro com o inusitado, com vistas a ampliar os horizontes éticos e estéticos dos estudantes” (BRASIL, 2018, p. 486), como propõe a BNCC, ao dispor sobre o componente língua portuguesa, para o Ensino Médio.

No que se refere ao âmbito artístico-literário, a BNCC postula que uma das funções do Ensino Médio é: “Ampliar o repertório de clássicos brasileiros e estrangeiros com obras mais complexas que representem desafio para os estudantes do ponto de vista dos códigos linguísticos, éticos e estéticos" (BRASIL, 2018, p. 526).

Assim, a formação do professor para conseguir lidar com as obras estrangeiras deve ser uma das preocupações dos cursos superiores que formam docentes para o Ensino Médio, uma vez que o professor de Português não deve estar restrito ao universo da língua portuguesa ou das literaturas e culturas de países de língua portuguesa. Ao contrário, deverá ampliar o repertório da turma, abrindo-lhes portas para outras culturas. Para tanto, é mister que a formação do(a) professor(a) seja tão rica quanto possível no intuito de prepará-lo(a) para lidar com uma gama ampla de elementos de diversas línguas, literaturas e culturas presentes nos manuais didáticos, ou pelo menos de identificar algumas delas e poder explorá-las com mais propriedade. 
Dessa forma, é esperado que um(a) professor(a) que tenha cursado uma graduação dupla em Letras Português-Italiano tenha mais facilidades de apontar as relações entre Itália e o Brasil, ou tenha mais conhecimentos para aprofundar discussões no âmbito linguístico, literário e artístico no que concerne à presença italiana no manual.

Em mais da metade das seções pesquisadas na coleção, há menções a elementos italianos. Isso nos remete quase que imediatamente à questão da formação de professores para o Ensino Básico, visto que são esses profissionais que irão mediar os conteúdos presentes no livro didático, lidando, entre outras coisas, com a expressiva presença italiana.

Uma outra constatação diz respeito ao fato de que, ainda que essa presença seja considerável, o manual Esferas das Linguagens a limita, quase sempre, à realidade paulista/paulistana ao evocar a imigração italiana em São Paulo, ao mencionar o dialeto ítalo-paulistano nascido na capital paulista do início do século XX e ao citar o livro Braz, Bexiga e Barra Funda, que retrata essa realidade. $O$ professor formado em italiano, e que utiliza o livro em outras regiões do país, poderia extrapolar a comparação entre Itália-São Paulo e aproximar-se da realidade local de seus estados em que as marcas da Itália também estão vivas como, por exemplo, o Espírito Santo ou o sul de nosso país.

Diante dessas considerações, vale apontar que os cursos de licenciatura dupla configuram-se como campo fértil para lidar com questões de diálogo entre a cultura brasileira e as culturas estrangeiras, principalmente, nos aspectos linguísticos e literários. Isto é, os profissionais com licenciatura dupla são preparados, desde o início da graduação, para lidar com conteúdos que, muitas vezes, não são previstos nos cursos de licenciaturas simples. 


\section{Referências}

BRASIL. Matriz de referência para o Enem. Ministério da Educação/Instituto Nacional de Estudos e Pesquisas Educacionais Anísio Teixeira, 2015. Disponível em: http://download.inep.gov.br/educacao_ basica/enem/downloads/2012/matriz_referencia_enem.pdf. Acesso em 20/09/2018.

BRASIL, Estudos sociodemográficos e análises espaciais referentes aos municípios com a existência de comunidades remanescentes de quilombos - Relatório técnico preliminar, 2007. Disponível em :

https://www.mdh.gov.br/biblioteca/igualdade-racial/estudos-sociodemograficos-e-analisesespaciais-referentes-aos-municipios-com-a-existencia-de-comunidades-remanescentes-de-quilombosrelatorio-tecnico-preliminar-ibge. Acesso em 07/08/2019.

BRASIL. Base Nacional Comum Curricular. Ministério da Educação, 2018. Disponível em: http:// basenacionalcomum.mec.gov.br/images/BNCC_EI_EF_110518_versaofinal_site.pdf. Acesso em : 07 ago. 2019.

CANDAU, Vera Maria Ferrão. Ser professor/a hoje: novos confrontos entre saberes, culturas $e$ práticas. Educação (Porto Alegre, impresso), v. 37, n. 1, p. 33-41, jan./abr. 2014.

Progetto ITENETS. Gli italiani in Brasile, 2003. Disponível em: <https://docplayer.com.br/69572Gli-italiani-in-brasile.html . Acesso em 12 nov. 2019.

CAMPOS, M. I. B.; ASSUMPÇÃO, N. Esferas das linguagens. São Paulo: FTD, 2016, vol.1, 2 e 3.

FREITAS, N. K., RODRIGUES, M. H. O livro didático ao longo do tempo: a forma do conteúdo. Revista da Pesquisa. Udesc, 2008. Disponível em: http://www1.udesc.br/arquivos/portal_antigo/ Seminario18/18SIC/PDF/074_Neli_Klix_Freitas.pdf. Acesso em 27/09/2018.

GIL, Antônio Carlos. Como elaborar projetos de pesquisa. São Paulo: Ed.Atlas, 2002.

BRASIL. Plano nacional do livro didático do Ensino Médio. Disponível em http://www.fnde.gov.br/ pnld-2018/. Acesso em 17/09/2019.

LAJOLO, Marisa. Livro Didático: um (quase) manual de usuário. In: Em aberto. n.16, Brasília, 1996. Disponível em: http://www.rbep.inep.gov.br/index.php/emaberto/article/viewFile/2061/2030. Acesso em 24/09/2019.

MARCONI, Marina de Andrade., LAKATOS, Eva Maria. Fundamentos de metodologia científica. São Paulo: Ed. Atlas, 2003.

Recebido em: 08/08/2019

Aprovado em: 13/10/2019 